\title{
Globalization, Labour Market Segmentation, Unemployment and Wage Inequality: A Theoretical Analysis
}

\author{
Rakhi Banerjee \\ Gurudas College, Kolkata

\section{Ranjanendra Narayan Nag} \\ St. Xavier's College
}

In this paper we build up a three-sector general equilibrium framework to examine impact of agricultural trade liberalization, tariff rate restructuring and inflow of Foreign Direct Investment on unemployment and wage inequality in an emerging market economy. The paper shows that agricultural trade liberalization and tariff rate restructuring reduces the skilled-unskilled wage gap whereas increase in inflow of foreign capital may lead to worsening of income distribution. Multiple cross effects, factor specificity and factor intensity ranking play important roles in determining changes in output composition, factor rewards and unemployment in the wake of economic reforms.

- JEL Classification: F16, F21

- Keywords: Economic Reforms, Efficiency Wage and Unemployment

\section{Introduction}

Persistence of unemployment and wage gap between skilled and unskilled labour are two disturbing features of an emerging market economy. Two types of unemployment can be easily identified. One is unemployment of skilled labor which can be attributed to efficiency wage; the other one is unemployment of

\footnotetext{
*Corresponding address: Rakhi Banerjee; Garpar Road,Kolkata-700009, West Bengal, India, E-mail: rakhi.banerjee77@gmail.com / Ranjanendra Narayan Nag; Ranjanendra Narayan Nag St. Xavier's College (Autonomous), P-36, CIT Scheme, VI M.S, Kolkata-700054, India, E-mail: rnnag12@gmail.com. (C2011-Center for Economic Integration, Sejong Institution, Sejong University, All Rights Reserved.
} 
unskilled labour which arises due to unionized wage. ${ }^{1}$ Casual empiricism suggests that rate of unemployment tends to rise with an increase in education and skill. Various rounds of NSSO surveys in India reveal that unemployment rate in both urban and rural India is higher among workers educated beyond the secondary level compared to workers with lesser degree of educational achievements. The NSSO 61st Round report, Employment and Unemployment Situation among social groups in India 2004-05, suggests that this trend can be attributed to the fact that workers with higher degree of education become more selective while choosing a job. A labour market study in Ethiopia suggests that unemployment is higher among educated first time job seekers (See, Serneels, 2007). A pertinent observation in this context is that employment of skilled labour is to a great extent demand driven. For example, the recent global meltdown of 2008 has severely affected the employment generating power of skill intensive sectors like the information and technology sector across countries.

First, we note that different types of unemployment depend on nature of labour market. In the Harris-Todaro framework, urban unemployment of unskilled labour is due to unionized wage. The Harris- Todaro framework has been extended in many directions so as to analyze implications of different measures of liberalization. Some notable contributions include Beladi and Marjit (1996), Marjit and Acharyya (2002), Chaudhuri (2007). However, these works have not paid any attention to the existence of unemployment of skilled labour.

The existence of unemployment of skilled laborer has been explained in terms of efficiency wage theories. Shapiro and Stiglitz (1984) assume that the work-effort of a worker varies positively with wage rate and unemployment rate. Moreover, efficiency wage theory has also been explained with the help of 'fair wage hypothesis (See, Akerlof and Yellen, 1990). Agell and Lundborg (1995) have incorporated the fair wage hypothesis in a $2 \times 2$ Hechscher-Ohlin-Samuelson structure to examine robustness of trade theorems. Chaudhuri and Banerjee (2010a, b) used a general equilibrium framework to explain unemployment of both skilled and unskilled labour.

It needs to be highlighted at this junction that development with rising income inequality is not dynamically sustainable. Once, we relate the issue of inclusive development to inequality, many other dimensions open up. One such dimension is

${ }^{1}$ It has been observed that widespread unemployment exists in many countries where union power is weak. The most obvious explanation is that firms bid up wage against each other. This is particularly true in case of skilled labour. 
wage inequality. Empirical studies of Robbins (1994a,b, 1995 a,b, 1996a,b) have focused on the incidence of wage inequality in the East Asian countries, Latin American countries and India. Event studies have revealed that removal of tariff restrictions from sectors that use unskilled labour intensively, growth in foreign investment and decline in union strength of unskilled workers are the prime factors responsible for the growing incidence of wage inequality. Reference in this context may be made to the works of Robbins (1994a, b), Feenstra and Hanson (1997). A legitimate academic inquiry is how to explain wage gap using general equilibrium framework. Theoretical literature on wage inequality induced by globalization includes the works of Feenstra and Hanson (1996), Marjit (2003), Marjit, Beladi and Chaudhuri (2004), Chaudhuri and Yabuuchi (2008), among others. However, what is missing in this literature is existence of unemployment of skilled labour.

The present paper uses a three-sector general equilibrium framework to examine impact of inflow of Foreign Direct Investment (FDI), agricultural trade liberalization and tariff rate restructuring on unemployment and wage inequality in an emerging market economy. We show that the effect on unemployment and income distribution depends on specific measure of economic reform that is undertaken. The present paper is an improvement over the existing literature since the issues of unemployment of both skilled and unskilled labour and wage inequality are simultaneously addressed in presence of endogenous inflow of foreign capital and unemployment of skilled labour. Now, few comments on foreign direct investment are in order.

The significant changes in the economic policies of developing countries in the direction of greater openness to trade and capital flows have motivated us to endogenise the inflow of foreign capital. In the face of inadequacy of domestic resources to finance long-term development projects, the relative importance of foreign direct investment (FDI) has increased rapidly for emerging market economies. Naturally, these economies have been trying to attract FDI through polices such as investor friendly investment laws, deregulation of investment flows, higher rates of return on foreign capital and encouragement to joint ventures with foreign firms. It needs to be noted that among the different determinants of FDI, host country's comparative advantage in international production and domestic investment climate are of special importance. Domestic investment climate encompasses both foreign investment regime and the general investment 
environment. ${ }^{2}$ In the times of globalization, "efficiency- seeking investment" has become important for emerging market economies. The product line, which has attracted the attention of foreign investors, is the service sector. We also note that labour market reforms have been implemented in the export-oriented sector that uses skilled labour. However, the traditional manufacturing sector is plagued by trade union activities. Thus, urban wage of unskilled labour is sticky and there is a wage gap between the industrial and the agricultural sector. The higher urban wage of unskilled worker leads to rural-urban migration. In the present paper we depart from the flexible specialization hypothesis according to which skilled labour is intersectorally mobile. The flexible specialization hypothesis is replaced by the hypothesis of "luxury unemployment" of skilled labour. ${ }^{3}$

The paper is organized as follows. In section II, we set up a three-sector general equilibrium model. In section III, we carry out comparative static exercises to explore the impact of inflow of foreign capital, agricultural trade liberalization and tariff rate restructuring on sectoral composition of output, unemployment level and factor rewards in a transitional economy. Section IV concludes the paper.

\section{The Model}

We consider a small open economy consisting of three sectors. Sector I is an industry that produces a skill intensive product, whereas sector II and III are traditional manufacturing sector and agricultural sector respectively. All the sectors are traded. We can realistically assume that sector I is export oriented; sector II is import competing while sector III is export oriented.

Next, we consider use of inputs. Domestic capital, foreign capital, skilled labour and unskilled labour are the four factors of production. There is substitutability between skilled labour, unskilled labour and domestic capital. However, we assume

\footnotetext{
${ }^{2}$ Foreign investment regime includes rules governing foreign investments and specific incentive for foreign investors. The general investment environment refers to attributes such as political stability and macroeconomic environment..

${ }^{3}$ According to flexible specialization hypothesis, skilled labour can move between sectors of production. In other words, acquisition of skill enables a person to do any kind of work. However, empirical literature hardly lends support to this hypothesis. A skilled worker chooses to remain in a state of unemployment in absence of job of his choice. In other words, a skilled worker who does not find a job in the formal sector may not seek employment in the informal sector and hence skilled labour is a specific factor. (see Agenor and Montiel,1999).
} 
that foreign capital is not substitutable. ${ }^{4}$ Inflow of foreign capital depends on a host of factors. In this model, we consider two factors that determine FDI. One factor is the perception of foreign investors about the "general investment environment" of the economy. This encompasses attributes such as political stability and institutional quality. The other factor that affects foreign capital inflow is the relative return on foreign capital. Domestic capital, skilled labour and foreign capital are used for the production of the skill-intensive product. Traditional manufacturing sector and the export-oriented agricultural sector uses domestic capital and unskilled labour for production.

The following symbols are used for the formal representation of the model.

$Y_{i}=$ output produced in $\mathrm{i}^{\text {th }}$ sector, $\mathrm{i}=1,2,3$;

$P_{i}^{*}=$ world price of $\mathrm{i}^{\text {th }}$ good, $\mathrm{i}=1,2,3$;

$K^{*}=$ supply of foreign capital

$\omega=$ wage of skilled workers;

$w=$ rural wage of unskilled labour;

$\bar{w}=$ urban wage of unskilled labour;

$r=$ return to domestic capital;

$R=$ return to foreign capital;

$a_{i j}=$ the amount of $\mathrm{i}^{\text {th }}$ factor required to produce 1 unit of output in sector $j$, $\left.i=N, K, K^{*}, L ; j=1,2,3\right)$;

$e=$ efficiency index of skilled workers;

$\tau=$ shift parameter;

$\bar{N}=$ endowment of skilled labour;

$N_{e}=$ level of employment of skilled labour;

$\bar{L}=$ unskilled labour endowment of the economy;

$L_{e}=$ level of employment of unskilled labour;

$\bar{K}=$ domestic capital endowment of the economy;

$\theta_{i j}=$ distribution share of factor $i$ in production of $Y_{i}\left(i=N, K, K^{*}, L ; j=1,2,3\right)$;

$\eta_{i j}=$ proportion of factor $i$ employed in sector $j\left(i=N, K, K^{*} L ; j=1,2,3\right)$;

$\sigma_{i j}^{k}=$ elasticity of substitution between factors $i$ and $j$ in sector $k(i, j=N, K, L$; $k=1,2,3)$

$t=$ tariff on sector 2

\footnotetext{
${ }^{4}$ The Information and Technology (IT) sector and Information Technology Enabled Services (ITES) are set up with the help of foreign capital. Foreign capital is a specific factor used in skill intensive sector such as in IT and ITES sector. Foreign capital cannot be replaced by another domestic factor of production.
} 
$\hat{a}=\frac{d a}{a}$, proportionate change in a; where a denotes any variable

$e_{1}=$ change in level of effort of skilled labour with change in wage of skilled labour

$e_{2}=$ change in effort of skilled labour with change in employment level of skilled labour

$e_{k^{*}}^{\tau}=$ Elasticity of foreign capital inflow with respect to the general investment environment

$e_{k^{*}}^{R}=$ Elasticity of foreign capital inflow with respect to the rate of return on foreign capital

$\gamma=$ Elasticity of effort with respect to employment of skilled labour.

The general equilibrium structure of the model is as follows.

Since, markets are competitive, equality between unit cost and price holds. Equations (1)- (3) represent the price system:-

$$
\begin{gathered}
\frac{\omega}{e\left(\omega, N_{e}\right)} a_{N 1}+r a_{K 1}+R a_{K^{*} 1}=P_{1}^{*} \\
\bar{w} a_{L 2}+r a_{K 2}=p_{2}^{*}(1+t) \\
w a_{l 3}+r a_{K 3}=p_{3}^{*}
\end{gathered}
$$

Following Shapiro and Stiglitz (1984) we assume that the effort function of a skilled laborer depends positively on the skilled wage rate and unemployment rate of skilled labour. Thus, the effort function is:

$e=f\left(\omega, N_{e}\right)$

The effort function satisfies the following restrictions:

$e_{1}>0$ and $e_{2}<0, e_{11}<0, e_{22}<0, e_{12}=e_{21}=0$

First, we explain determination of wage of skilled labour in terms of efficiency wage theory. Equation (a) indicates that in equilibrium the elasticity of effort with respect to the product wage must be equal to unity which is the standard Solow condition:

$$
\frac{\omega \cdot e_{1}\left(\omega, N_{e}\right)}{e\left(\omega, N_{e}\right)}=1
$$

This fixes efficiency wage for any given employment of skilled labour. Equation 
(a) is obtained by minimizing $\frac{\omega}{e(\omega)}$.

The endowment system of the economy is as follows.

$$
\begin{aligned}
a_{k^{*} 1} \cdot Y_{1}= & K^{*}(R, \tau) \quad \ldots . .(4), \text { where } \frac{\delta K^{*}}{\delta R}>0, \frac{\delta K^{*}}{\delta \tau}>0^{6} \\
& a_{K 1} \cdot Y_{1}+a_{K 2} \cdot Y_{2}+a_{K 3} \cdot Y_{3}=\bar{K}
\end{aligned}
$$

The rural -urban migration stops when expected urban wage equals the rural wage and thus, equation (6) represents the Harris-Todaro migration equilibrium:

$$
\bar{w} a_{L 2} \cdot Y_{2}+w a_{L 3} \cdot Y_{3}=w \cdot \bar{L}
$$

Total employment of unskilled workers is given by the following equation:

$$
a_{L 2} \cdot Y_{2}+a_{L 3} \cdot Y_{3}=L_{e}<\bar{L}
$$

The employment of skilled labour in efficiency unit is expressed as follows:

$$
\frac{a_{N 1}}{e\left(\omega, N_{e}\right)} Y_{1}=N_{e}<\bar{N}
$$

The working of the model is this. The model has the standard decomposition property. Since $\bar{w}$ is given, equation (2) can be used to solve for. Once $r$ is known, equation (1) and equation (3) solve for $R$ and $w$ respectively. $Y_{1}$ is determined from equation (4). From equations (5) and (6) we solve $Y_{2}$ and $Y_{3}$. Equation (7) is used to determine $L_{e}$ while $N_{e}$ is obtained from equation (8).

\section{Comparative Statics}

We examine effects of agricultural trade liberalization, tariff rate restructuring and inflow of foreign capital on unemployment and wage inequality.

\footnotetext{
${ }^{5}$ We use an efficiency function which is a special case of the more general efficiency function considered in the fair wage hypothesis. In the fair wage hypothesis, rental rate on capital also affects effort function (see Chaudhuri and Banerjee (2010a.)

${ }^{6} \tau$ is the model specific rendition of "general investment environment" of the economy. An increase in $\tau$ would facilitate the flow of FDI into a transitional economy.
} 


\section{A. Agricultural trade liberalization}

First, we examine the effect of agricultural trade liberalization. The process of removing agricultural trade restrictions would allow farmers to take advantage of higher world prices. Thus, liberalizing agricultural trade would equalize the domestic agricultural price to the higher world price for a small open economy.

Proposition 1: Agricultural trade liberalization increases rural wage of unskilled workers. It reduces unemployment of unskilled workers if modern agriculture is labour intensive compared to the traditional manufacturing sector in value terms. ${ }^{7}$ However, agricultural trade liberalization has no effect on the skill- intensive sector.

Comments: Agricultural trade liberalization would allow farmers to take advantage of higher world prices of the export oriented agricultural product.

Using equations (1) to (8) we have: ${ }^{8}$

$$
\begin{gathered}
\hat{w}=\frac{1}{\theta_{L 3}} \hat{p}_{3}^{*} \\
\hat{Y}_{2}=-\frac{1}{D} \frac{p_{3}^{*}}{\theta_{L 3}}\left[\left(\lambda_{L 2} \theta_{K 2} \frac{\sigma_{L, K}^{2}}{\theta_{K 2}+\theta_{L 2}}+\frac{\lambda_{L 3} \theta_{K 3} \sigma_{L, K}^{3}}{\theta_{L 3}+\theta_{K 3}}\right)+\left(\lambda_{K 2} \theta_{L 2} \frac{\sigma_{L, K}^{2}}{\theta_{K 2}+\theta_{L 2}}+\frac{\lambda_{K 3} \theta_{L 3} \sigma_{L, K}^{3}}{\theta_{L 3}+\theta_{K 3}}\right)\right] \\
\hat{Y}_{3}=\frac{1}{\lambda_{L 3}}\left(\lambda_{L 2} \theta_{K 2} \frac{\sigma_{L, K}^{2}}{\theta_{K 2}+\theta_{L 2}}+\frac{\lambda_{L 3} \theta_{K 3} \sigma_{L, K}^{3}}{\theta_{L 3}+\theta_{K 3}}\right) \frac{1}{\theta_{L 3}} \hat{p}_{3}^{*} \\
-\frac{\lambda_{L 2}}{\lambda_{L 3}} \frac{\bar{w}}{w}\left[-\frac{1}{D} \frac{\hat{p}_{3}^{*}}{\theta_{L 3}}\left[\left(\lambda_{L 2} \theta_{K 2} \frac{\sigma_{L, K}^{2}}{\theta_{K 2}+\theta_{L 2}}+\frac{\lambda_{L 3} \theta_{K 3} \sigma_{L, K}^{3}}{\theta_{L 3}+\theta_{K 3}}\right)+\left(\lambda_{K 2} \theta_{L 2} \frac{\sigma_{L, K}^{2}}{\theta_{K 2}+\theta_{L 2}}+\frac{\lambda_{K 3} \theta_{L 3} \sigma_{L, K}^{3}}{\theta_{L 3}+\theta_{K 3}}\right]\right.\right.
\end{gathered}
$$

Where,

$$
\begin{gathered}
D=\eta_{K 2} \eta_{L 3}-\frac{\bar{w}}{w} \eta_{L 2} \eta_{K 3}>0 \\
\hat{L}_{e}=\lambda_{L 2}\left[1-\frac{\bar{w}}{w}\left[-\frac{1}{D} \frac{\hat{p}_{3}^{*}}{\theta_{L 3}}\left[\left(\lambda_{L 2} \theta_{K 2} \frac{\sigma_{L, K}^{2}}{\theta_{K 2}+\theta_{L 2}}+\frac{\lambda_{L 3} \theta_{K 3} \sigma_{L, K}^{3}}{\theta_{L 3}+\theta_{K 3}}\right)+\left(\lambda_{K 2} \theta_{L 2} \frac{\sigma_{L, K}^{2}}{\theta_{K 2}+\theta_{L 2}}+\frac{\lambda_{K 3} \theta_{L 3} \sigma_{L, K}^{3}}{\theta_{L 3}+\theta_{K 3}}\right)\right]\right]\right.
\end{gathered}
$$

From the price system it follows that wage rate of unskilled laborers employed in the export oriented agricultural sector rises, whereas rent on domestic capital and foreign capital remains unchanged. From the standard Solow condition we find that

\footnotetext{
${ }^{7}$ Since unskilled labour in the manufacturing sector and export oriented agricultural sector earn different wage, factor intensity ranking needs to be couched in value terms. If the import competing manufacturing sector is capital intensive compared to export oriented agricultural sector, then we have$$
\frac{\bar{w} a_{L 2}}{a_{K 2}}<\frac{w a_{L 3}}{a_{k 3}}
$$

${ }^{8}$ See appendix for the derivation. 
the efficiency wage of skilled labour remains constant.

Agricultural trade liberalization does not affect the inflow of foreign capital into the economy. Hence, the production level of the skill intensive sector remains unchanged. From the preceding analysis we find that $\left(\frac{w}{r}\right)$ would increase and hence, labour coefficient in export oriented agricultural sector would decline which amounts to an effective increase in endowment of labour. Since the agricultural sector is labour intensive, it would expand in size and there would be a contraction of the traditional manufacturing sector since the endowment of domestic capital is unchanged.

Skilled labour is used in the production of skill- intensive, export- oriented sector only. Since the production level of skill intensive sector is unchanged, the level of employment of skilled workers also remains unaffected. Agricultural trade liberalization augments employment creation of the unskilled laborers. The explanation is this. It is well known that majority of the unskilled labour force in a developing country is absorbed in the agricultural sector. Again, the agricultural sector is labour intensive and its employment intensity is high compared to the traditional manufacturing sector. Thus, the increase in production level of the agricultural commodities in the wake of agricultural trade liberalization may increase the employment of unskilled workers. However, agricultural trade liberalization also produces a negative impact on the employment of unskilled laborers. An increase in the price of modern agricultural products, leads to an increase in $\left(\frac{w}{r}\right)$. An increase in $\left(\frac{w}{r}\right)$ would lead to a decrease in labour coefficient in export oriented agricultural sector and the urban manufacturing sector. Hence, the demand for unskilled labour decreases. In this model the positive effect of agricultural trade liberalization outweighs the negative effect and hence, unemployment of unskilled labour decreases.

Corollary 1: Expected wage of skilled labour is $p \omega$, where $p=$ probability of getting job in the skill intensive sector. Hence, expected wage of skilled labour $=\frac{N_{e}}{N} \omega$.

We set $\mathrm{N}=1$. The gap $(\mathrm{Z})$ between the skilled wage and unskilled wage is:

$\mathrm{Z}=N_{e} \omega-w^{9}$

Thus,

$$
d Z=N_{e} \omega\left[\hat{N}_{e}+\hat{\omega}\right]-w \hat{w}, d z=-w \frac{1}{\theta_{L 3}} \hat{p}_{3}^{*}
$$

${ }^{9}$ By envelope theorem we find that wage of unskilled laborer is equal to the wage of rural workers. 
The expected wage of skilled workers remain unchanged since both wage and unemployment of skilled labour do not change. On the other hand, the wage of unskilled workers increases. Hence, the wage gap between skilled and unskilled workers decreases.

\section{B. Tariff liberalization}

Next, we address the issue of trade liberalization i.e. fall in the tariff rate.

Proposition 2: If $\gamma<1$ and $\theta_{N 1}+\left(\theta_{K 1}+\theta_{K_{1}^{\prime}}-1\right)\left(e_{1} \omega+\omega^{2} e_{11}\right)-\frac{\theta_{K 1}}{\theta_{N 1}+\theta_{K 1}} \sigma_{N, K}^{1}(1-e)>0$, tariff rate restructuring reduces unemployment problem of skilled laborers provided

$$
\frac{\theta_{K 1} \sigma_{N, K}^{1}}{\left(\theta_{N 1}+\theta_{K 1}\right) \theta_{K 2}}\left[e\left(\theta_{K_{1}^{*}}+e_{k^{*}}^{R}\right) \theta_{K 2}-1\right]-e_{K^{*}}^{R} \theta_{K_{1}^{*}}<0
$$

If modern agriculture is labour intensive compared to the traditional manufacturing sector in value terms, the employment level of unskilled workers would increase.

Comments: Tariff rate restructuring would tend to equalize the domestic price of traditional manufacturing product to the world price of the manufacturing product. Hence, the price of the traditional manufacturing product would decrease.

From equations (1) to (8) we get:

$$
\begin{aligned}
& \hat{r}=\frac{1}{\theta_{K 2}} \hat{\mathrm{tt}} \\
& \hat{\omega}=\frac{1}{e_{K}^{R} \cdot L+\theta_{K_{1}^{N}} N e} \frac{1}{\theta_{K 2}} \hat{t} V \\
& \hat{R}=\left[-\frac{\theta_{K 1}}{\theta_{N 1}+\theta_{K 1}} \frac{1}{\theta_{K 2}} \sigma_{N . K}^{1}+N \frac{1}{e_{K^{R}}^{R} L+\theta_{K_{1}^{*}} N e} \frac{1}{\theta_{K 2}} V\right] \frac{1}{e_{K^{*}}^{R}} \hat{t} \\
& \hat{w}=\frac{\theta_{K 3}}{\theta_{K 2}+\theta_{L 3}} \hat{\mathrm{t}} \\
& \hat{Y}_{1}=\left[-\frac{\theta_{K 1}}{\theta_{N 1}+\theta_{K 1}} \frac{1}{\theta_{K 2}} \sigma_{N . K}^{1}+N \frac{1}{e_{K^{R}}^{R} L+\theta_{K_{1}^{*}} N e} \frac{1}{\theta_{K 2}} V\right] \hat{\mathfrak{t}} \\
& \hat{Y}_{2}=-\frac{1}{D}\left[-\hat{t}\left\{T \lambda_{K 2}+\lambda_{L 3} O\right\}+\lambda_{K 1} \lambda_{L 3}\left[-\frac{\theta_{K 1}}{\theta_{N 1}+\theta_{K 1}} \frac{1}{\theta_{K 2}} \sigma_{N . K}^{1}+N \frac{1}{e_{K^{R}}^{R} \cdot \theta_{K_{1}^{N}} \cdot N e} \frac{1}{\theta_{K 2}} V\right] \hat{\mathfrak{t}}\right] \\
& \hat{Y}_{3}=-T t \hat{t} \frac{1}{\lambda_{L 3}}-\frac{\bar{w}}{w} \frac{\lambda_{L 2}}{\lambda_{L 3}}\left\{-\frac{1}{D}\left[-\hat{t}\left\{T \lambda_{K 2}+\lambda_{L 3} O\right\}+\lambda_{K 1} \lambda_{L 3}\left[-\frac{\theta_{K 1}}{\theta_{N 1}+\theta_{K 1}} \frac{1}{\theta_{K 2}} \sigma_{N . K}^{1}+N \frac{1}{e_{K}^{R} \cdot L+\theta_{K_{1}} N e} \frac{1}{\theta_{K 2}} V\right] \hat{t}\right]\right\}
\end{aligned}
$$




$$
\begin{gathered}
\hat{N}_{e}=\frac{\omega^{2} e_{11}}{N_{e} e_{2}} \frac{1}{e_{K^{*}}^{R} L+\theta_{K_{1}^{*}} N e} \frac{1}{\theta_{K 2}} \hat{t} V \\
\hat{L}_{e}=\frac{1}{\theta_{K 2}} \hat{t} \lambda_{L 2} \theta_{K 2} \frac{1}{\theta_{K 2}+\theta_{L 2}} \sigma_{L, K}^{2}\left(1-\frac{\bar{w}}{w}\right)\left(1+\frac{\theta_{K 3}}{\theta_{L 3}}\right)+\frac{1}{D}\left[-t t\left\{T \lambda_{K 2}+\lambda_{L 3} O\right\}+\lambda_{K 1} \lambda_{L 3}\right. \\
\left.\left[-\frac{\theta_{K 1}}{\theta_{N 1}+\theta_{K 1}} \frac{1}{\theta_{K 2}} \sigma_{N . K}^{1}+N \frac{1}{e_{K^{R}}^{R} L+\theta_{K_{1}^{*}} N e} \frac{1}{\theta_{K 2}} V\right] \hat{t}\right] \lambda_{L 2}\left(1-\frac{\bar{w}}{w}\right)
\end{gathered}
$$

Where,

$$
\begin{gathered}
V=\frac{\theta_{K 1} \sigma_{N, K}^{1}}{\left(\theta_{N 1}+\theta_{K 1}\right) \theta_{K 2}}\left[e\left(\theta_{K_{1}}^{*}+e_{K^{*}}^{R}\right) \theta_{K 2}-1\right]-e_{K^{*}}^{R} \theta_{K_{1}}^{*} e \\
T=\frac{1}{\theta_{K 2}}\left\{\frac{\lambda_{L 2} \theta_{K 2}}{\theta_{K 2}+\theta_{L 2}} \sigma_{L, K}^{2}+\frac{\lambda_{L 3} \theta_{K 3} \sigma_{N, K}^{3}}{\theta_{L 3}+\theta_{K 3}}\right\}+\frac{\theta_{K 3}}{\theta_{L 3} \theta_{K 2}}\left\{\frac{\lambda_{L 2} \theta_{K 2} \sigma_{L, K}^{2}}{\theta_{K 2}+\theta_{L 2}}+\frac{\lambda_{L 3} \theta_{K 3} \sigma_{L, K}^{3}}{\theta_{L 3}+\theta_{K 3}}\right\} \\
\mathrm{O}=\frac{1}{\theta_{K 2}}\left\{\frac{\lambda_{K 2} \theta_{L 2}}{\theta_{K 2}+\theta_{L 2}} \sigma_{L, K}^{2}+\frac{\lambda_{K 3} \theta_{L 3} \sigma_{L, K}^{3}}{\theta_{L 3}+\theta_{K 3}}+\frac{\lambda_{K 1} \theta_{N 1} \sigma_{L, K}^{1}}{\theta_{N 1}+\theta_{K 1}}\right\}+\frac{\theta_{K 3}}{\theta_{L 3} \theta_{K 2}}\left\{\frac{\lambda_{K 2} \theta_{L 2} \sigma_{L, K}^{2}}{\theta_{K 2}+\theta_{L 2}}+\frac{\lambda_{L 3} \lambda_{K 3} \sigma_{L, K}^{3}}{\theta_{L 3}+\theta_{K 3}}\right\} \\
+\left[-\frac{\lambda_{K 1} \theta_{N 1}}{\theta_{N 1}+\theta_{K 1}} \sigma_{N, K}^{1} \frac{V}{\theta_{K 2}\left\{\theta_{K 1}^{*} e N+L e_{K}^{R}\right\}}\right] \\
\mathrm{L}=\eta_{K 2} \eta_{L 3}-\frac{\bar{w}}{w} \eta_{L 2} \eta_{K 3}>0 \\
+\left(\theta_{K 1}+\theta_{K_{1}^{*}}^{*} 1\right)\left(e_{1} \omega+\omega^{2} e_{11}\right)-(1-e) \frac{\theta_{K 1}}{\theta_{N 1}+\theta_{K 1}} \sigma_{N, K}^{1} \\
\mathrm{~N}=\frac{1}{\lambda_{N 1}}\left[\omega e_{1}+\frac{\omega^{2} e_{11}}{N_{e} e_{2}} e(1-\gamma)+\frac{\lambda_{N 1} Y_{1} \theta_{K 1} \sigma_{N, K}^{1}}{e\left(\theta_{N 1}+\theta_{K 1}\right)}\right]
\end{gathered}
$$

Tariff rate restructuring leads to a fall in the rate of return on domestic capital. Tariff rate restructuring also leads to an increase in wage rate of unskilled laborers. Since, rate of return on domestic capital declines, we conclude from equation (1) that sum of unit cost of skilled labour and that of foreign capital should increase. Change in rate of interest on domestic capital and wage of skilled labour entail change in factor coefficients. If

$$
\gamma<1 \text { and } \theta_{N 1}+\left(\theta_{K 1}+\theta_{K_{1}^{*}}-1\right)\left(e_{1} \omega+\omega^{2} e_{11}\right)-\frac{\theta_{K 1}}{\theta_{N 1}+\theta_{K 1}} \sigma_{N, K}^{1}>0
$$

both rate of return on foreign capital and wage of skilled laborer increase provided $\frac{\theta_{K 1} \sigma_{N, K}^{1}}{\left(\theta_{N 1}+\theta_{K 1}\right) \theta_{K 2}}\left[e\left(\theta_{K_{1}^{*}}+e_{K^{*}}^{R}\right) \theta_{K 2}-1\right]-e_{K^{*}}^{R} e \theta_{K_{1}^{*}}<0$.

This increase in the rate of return on foreign capital entails an increase in the 
supply of foreign capital which leads to expansion of the skill intensive sector and increase in employment of skilled labour. As the price of domestic capital decreases, there is a tendency of producers to substitute skilled laborers by domestic capital. Hence, there is negative effect on the employment opportunity of skilled laborer. However, in the present context, the negative effect is outweighed by the positive effect and employment of skilled laborers increase.

The increase in production level of the skill intensive product reduces the amount of domestic capital available for production both the traditional manufacturing sector and export oriented agricultural product. An increase in $\left(\frac{w}{r}\right)$ also decreases domestic capital available for both the traditional manufacturing sector and the export oriented agricultural sector. If the modern agriculture is labour intensive compared to the traditional manufacturing sector in value terms, the production of the manufacturing sector would contract whereas the production level of the exportoriented agricultural product would increase with tariff rate restructuring. The preceding analysis shows that the level of production of the labour intensive agricultural sector increases. Since the agricultural wage of unskilled labour is lower than the unionized wage, its ability to absorb labour is more. Thus tariff rate restructuring helps in reducing the unemployment level of unskilled workers.

Corollary 2: Next we consider effect on wage gap. The change in the wage gap between skilled and unskilled labour can be expressed as follows:

$$
d Z=N_{e} \omega\left[\hat{N}_{e}+\hat{\omega}\right]-w \hat{w}
$$

Thus,

$$
d Z=N_{e} \omega\left[\frac{\omega^{2} e_{11}}{N_{e} e_{2}}+1\right] \frac{1}{e_{K^{*}}^{R} L+\theta_{K_{1}^{*}} N e} \frac{1}{\theta_{K 2}} \hat{t} t V+w \frac{\theta_{K 3}}{\theta_{K 2} \theta_{L 3}} \hat{t}
$$

The expected wage of skilled labour and the wage of unskilled labour both increase. The sufficient condition for wage gap between skilled and unskilled labour to decrease is: $\left[\frac{\omega^{2} e_{11}}{N_{e} e_{2}}+1\right]<0$

\section{Increase in capital flow}

Next, we analyze the impact of an exogenous increase in foreign capital inflow.

Proposition 3: If $\gamma<1$, improvement in the general investment environment of the economy increases production of the skill intensive sector and reduces unemployment of skilled laborers provided 


$$
\theta_{N 1}+\left(\theta_{K 1}+\theta_{K_{1}^{*}}-1\right)\left(e_{1} \omega+\omega^{2} e_{11}\right)-\frac{\theta_{K 1}}{\theta_{N 1}+\theta_{K 1}} \sigma_{N, K}^{1}(1-e)>0
$$

If the modern agricultural sector is labour intensive compared to the traditional manufacturing sector in value terms, the employment level of unskilled workers would also increase.

Comment: An increase in $\tau$ implies that the perception of the investors about the general investment environment of the economy has improved. This would act as a facilitator in increasing flow of foreign capital.

Differentiating equations (1)-(8) we find: ${ }^{10}$

$$
\begin{aligned}
& \hat{\omega}=\frac{1}{e_{K^{*}}^{R} L+\theta_{K_{1}^{*}} e N}\left(\theta_{K^{\prime}}^{1} \cdot e_{K^{*}}^{\tau} \hat{\tau}\right) \\
& \hat{R}=\frac{\mathrm{L}}{e_{K^{*}}^{R} L+\theta_{K_{1}^{*}} e N}\left(\theta_{K^{*}}^{1} \cdot e e_{K^{*}}^{\tau} \cdot \hat{\tau}\right) \frac{1}{\theta_{K_{1}^{*}}^{e e}} \\
& \hat{Y}_{1}=e_{K^{*} \tau}^{\tau}\left[\frac{L}{e_{K^{R}}^{R} \cdot L+\theta_{K_{1}^{1}}^{1} \cdot N}+1\right] \\
& \left.\hat{Y}_{2}=-\frac{1}{D} e^{\tau} \cdot \hat{\tau} \cdot \frac{e_{K^{*}}^{R}}{e_{K^{*}}^{R} L+\theta_{K_{1}^{*}} e N}+1\right] \lambda_{K 1} \lambda_{L 3} \\
& \hat{Y}_{3}=\frac{\bar{w}}{w} \frac{\lambda_{L 2}}{\lambda_{L 3}} \frac{1}{D} e^{\tau}{ }_{K^{*}}^{*} \tilde{\tau}\left[\frac{e_{K^{*}}^{R}}{e_{K^{*}}^{R}{ }^{*}+\theta_{K_{1}^{*}} e N}+1\right] \lambda_{K 1} \lambda_{L 3} \\
& \hat{N}_{e}=\frac{\omega^{2} e_{11}}{N_{e} e_{2}} \frac{1}{e_{K^{*}}^{R} L+\theta_{K^{*}}^{1} e N}\left(\theta_{K^{*}}^{1} e e_{K^{*}}^{\tau} \hat{\tau}\right) \\
& \hat{L}_{e}=-\lambda_{L 2}\left[1-\frac{1}{\bar{w}} w\right] \frac{1}{D} e^{\tau} \hat{K}^{*}\left[\frac{e_{K^{*}}^{R}}{e_{K^{*}}^{R} L+\theta_{K_{1}^{*}} e N}+1\right] \lambda_{K 1} \lambda_{L 3} \\
& \mathrm{D}=\eta_{K 2} \eta_{L 3}-\frac{\bar{w}}{w} \eta_{L 2} \eta_{K 3}>0 \\
& \mathrm{~L}=\theta_{N 1}+\left(\theta_{K 1}+\theta_{K_{1}^{*}}-1\right)\left(e_{1} \omega+\omega^{2} e_{11}\right)-(1-e) \frac{\theta_{K 1}}{\theta_{N 1}+\theta_{K 1}} \sigma_{N, K}^{1} \\
& \mathrm{~N}=\frac{1}{\lambda_{N 1}}\left[\omega e_{1}+\frac{\omega^{2} e_{11}}{N_{e} e_{2}} e(1-\gamma)+\frac{\theta_{K 1} \sigma_{N, K}^{1}}{e\left(\theta_{N 1}+\theta_{K 1}\right)}\right]
\end{aligned}
$$

${ }^{10}$ See appendix for detailed derivation. 
From the price system we can conclude that wage of unskilled workers and rate of return on domestic capital remains unchanged. Hence, from equation (1) we can state that sum of unit cost of skilled labour and that of foreign capital should remain constant.

If $\gamma<1$ and $\theta_{N 1}+\left(\theta_{K 1}+\theta_{K_{1}^{*}}-1\right)\left(e_{1} \omega+\omega^{2} e_{11}\right)-\frac{\theta_{K 1}}{\theta_{N 1}+\theta_{K 1}} \sigma_{N, K}^{1}(1-e)>0$, wage of unskilled workers increase and rate of return on foreign capital decrease. Since, an increase in $\tau$ attracts foreign capital into the economy, there is a tendency of the skill intensive sector to expand in size. On the other hand, decrease in rate of return on foreign capital, dampens the production level of the skill intensive sector by reducing the availability of foreign capital. However, the primary effect of an improvement in the general investment environment of the economy dominates the secondary effect of a decline in rate of return on foreign capital. Hence, the production of the skill intensive sector expands. The increase in production of the skill intensive sector reduces the problem of unemployment of skilled laborers.

It should be brought into focus that expansion in the production level of the skill intensive product would reduce the amount of domestic capital available for production both the traditional manufacturing sector and export oriented agricultural product. Since, traditional manufacturing sector is capital intensive compared to the export oriented agricultural product, the production of the manufacturing sector would contract and the production level of the export-oriented agricultural product would increase. Expansion in the production of labour intensive agricultural sector would lead to an increase in the employment level of unskilled laborers since the ability to absorb labour of the agricultural sector is higher compared to the traditional manufacturing sector.

\section{Corollary 3:}

Next we examine effect on the gap between the skilled wage and unskilled wage $\mathrm{Z}=N_{e} \omega-w$.

Thus,

$$
\begin{aligned}
& d Z=N_{e} \omega\left[\hat{N}_{e}+\hat{\omega}\right]-w \hat{w} \\
& d Z=\left[\frac{\omega^{2} e_{11}}{N_{e} e_{2}} \frac{1}{e_{K^{*}}^{R} L+\theta_{K_{1}^{*}} e N}\left(\theta_{K_{1}^{*}} e e_{K^{*}}^{\tau} \hat{\tau}\right)+\frac{1}{e_{K^{*}}^{R} L+\theta_{K_{1}^{*}} e N}\left(\theta_{K^{*}}^{1} e e_{K^{*}}^{\tau} \hat{\tau}\right)\right] N_{e} \omega
\end{aligned}
$$

From proposition 3 we find that expected wage of skilled labour increases whereas the wage of unskilled labour remains unchanged. Hence, the gap between 
skilled wage and unskilled wage increases leading to a deterioration of income distribution.

\section{Conclusion}

The purpose of the paper has been to provide a theoretical discussion on the possible impact of exogenous increase in capital stock, tariff rate restructuring and agricultural trade liberalization on unemployment and wage inequality in a transitional economy. The paper shows that if modern agriculture is labour intensive compared to the traditional manufacturing sector in value terms, selected measures of economic measures of economic reforms reduce the problem of unemployment of unskilled laborers as well as unemployment among skilled workers. However, the effect on income distribution depends on the specific policy measure chosen. Agricultural trade liberalization reduces the wage gap between skilled and unskilled labour. However, improvement in the general investment environment of the economy may lead to worsening of income distribution between skilled and unskilled labour. The results in this paper are sensitive to the assumptions of factor intensity ranking and complementarity that is embedded in a three-sector general equilibrium model. The broad policy message of the paper is that if policy makers in emerging market economies judiously work out sequence, speed and modalities of globalization, economic reforms would produce maximum positive linkage effects for transitional economies.

\section{Acknowledgement}

We are also grateful to the anonymous referees for their comments on an earlier version of the paper. The usual disclaimer applies.

Received 11 November 2010, Revised 4 April 2011, Accepted 10 July 2011

\section{References}

Agell, J., Lundborg P. (1992), "Fair wages, involuntary unemployment and tax policy in the simple general equilibrium model", Journal of Public Economics, 47, pp. 299320.

Agell, J., Lundborg, P. (1995), "Fair wages in the open economy, Economica", 62, pp. 325-351. 
Agenor P.R, and Montiel (1999), "Development Macroeconomics", Second Edition, New Jersey: Princeton University Press.

Agenor P.R, Aizenman J (1999), "Macroeconomic Adjustment with Segmented Labour Markets", Journal of Development Economics, 58, pp. 277-296

Akerlof, G., Yellen, J. (1990), "The fair wage effort hypothesis and unemployment", Quarterly Journal of Economics, 105, pp. 255-284.

Beladi, H and Marjit, S. (1996), "An analysis of rural urban migration and Protection", The Canadian Journal of Economics, 29(4), pp. 930-940

Beladi, H and Marjit, S and Ralph, F. (1998), "Foreign Capital Accumulation and National Income: Does Unemployment Matter?”, KEIO Economic Studies, 35(1), pp. 19-27.

Beladi, H., Chaudhuri, S., Yabuuchi, S. (2008), "Can international factor mobility reduce wage inequality in a dual economy?", Review of International Economics, 16(5), pp. 893-903.

Chaudhuri, S. (2007), "Foreign Capital, welfare and urban unemployment in the presence of agricultural dualism", Japan and the world economy, 19, pp. 149-165

Chaudhuri, S., Yabuuchi, S., (2007), "Economic liberalization and wage inequality in the presence of labour market imperfection", International Review of Economics and Finance, 16, pp. 592-603.

Chaudhuri, S., Yabuuchi, S. (2008), "Foreign capital and skilled-unskilled wage inequality in a developing economy with non-traded goods in Marjit", S., Yu, E. (Eds.), Contemporary and Emerging Issues in Trade Theory and Policy, Emerald Group Publishing Limited, UK.

Chaudhuri, S , Banerjee, D. (2010a), "Foreign capital inow, skilled-unskilled wage inequality and unemployment of unskilled labour in a fair wage model", Economic Modelling, 27, pp. 477-486.

Chaudhuri, S, Banerjee, D. (2010b), "FDI in agricultural land, welfare and unemployment in a developing economy", Research in Economics, 64, pp. 229-239.

Feenstra, R.C and Hanson, G.H (1996), "Foreign Investment, Outsourcing and Relative Wages, in Feenstra, Grossman and Irwin (eds) Political Economy of Trade Policies: Essays in Honour of J.N.Bhagawati", Cambridge MIT Press.

Feenstra, R.C and Hanson, G.H (1997), "Foreign Direct Investment and Relative wages: evidence from Mexico's Maquiladoras", Journal of International Economics, 42(3/ 4), pp. 371-393.

Feenstra, R.C and Hanson, G.H. (2003), "Global Production Sharing and Rising Inequality: A Survey of Trade and Wages, in Choi, E.K and Harrigan", J (eds), Handbook of International Trade, Basil Blackwell, London.

Harris, J. R, Todaro, M.P. (1970), "Migration, Unemployment, and Development: A Two Sector Analysis", The American Economic Review, 60(1), pp. 126-142.

Jones, R.W. (1965), "The Structure of Simple General Equilibrium Models", Journal of Political Economy, 73, pp. 557-72.

Jones, R.W. (1984), "Protection and the harmful effects of endogenous capital flows", 
Economic Letters, 15, pp. 325-330.

Jones, R.W and Marjit, S. (2003), "Economic Development, trade and Wages", German Economic Review, 4(1), pp. 1-17.

Marjit S, Acharyya R. (2002), "International Trade, Wage Inequality and the Developing Economy- A General Equilibrium Approach", Physica-Verlag.

Marjit, S. (2003), "Economic Development, Trade and Wages", German Economic Review, 4, pp. 1-17.

Marjit, S., Beladi, H., Chakrabarti, A. (2004), "Trade and wage inequality in developing Countries", Economic Inquiry, 42, pp. 295-303.

Marjit, S. (2008), "International Trade and Economic Development- Essays in Theory and Policy", OUP Publications.

Mussa, M. (1974), "Tariffs and the Distribution of Income: The importance of factor Specificity, Substitutability, and Intensity in the short and long run", Journal of Political Economy, 82(6), pp. 1191-1203.

NSS $61^{\text {st }}$ Round: Employment and Unemployment Situation Among Social Groups in India 2004-05 , Report No. 516(61/10/2), source: http://mospi.gov.in/national_data_bank/ndbrpts-61.htm, accessed on 2.7.11 at 20.30 p.m

Robbins, D. (1994a), "Malaysian Wage Structure and it's causes", Working Paper: Harvard Institute of International Development.

Robbins, D. (1994b), "Philippine wage and employment structure 1978-1983", Working Paper: Harvard Institute of International Development.

Robbins, D. (1995a), "Earnings Dispersion in Chile after trade Liberalisation", Working Paper: Harvard Institute of International Development

Robbins, D. (1995b), "Trade, Trade Liberalisation and inequality in Latin America and East Asia: A Synthesis of seven country studies”, Working Paper: Harvard Institute of International Development.

Robbins, D. (1996a), "Stolper Samuelson lost in the tropics- trade liberalisation and wages in Columbia", Working Paper: Harvard Institute of International Development.

Robbins, D. (1996b), "HOS hits facts: Facts win: Evidence on trade and wages in developing World", Working Paper: Harvard Institute of International Development.

Serneels, P.M. (2007), "The nature of unemployment among young men in urban Ethiopia", Review of Development Economics, 11(1), pp. 170-186.

Shapiro, C., Stiglitz, J.E. (1984), "Equilibrium unemployment as a worker discipline device", American Economic Review, 74, pp. 433-444.

Yabuuchi, S., Chaudhuri, S. (2007), "International migration of labour and skilledunskilled wage inequality in a developing economy", Economic Modeling, 24(1), pp. 128-137.

\section{Appendix}


Since, markets are competitive, equality between unit cost and price holds. Equations (1)- (3) represent the price system:-

$$
\begin{gathered}
\frac{\omega}{e\left(\omega, N_{e}\right)} a_{N 1}+r a_{K 1}+R a_{K^{* 1}}=P_{1}^{*} \\
\bar{w} a_{L 2}+r a_{K 2}=P_{2}^{*}(1+t) \\
w a_{l 3}+r a_{K 3}=P_{3}^{*} \\
\frac{\omega \cdot e_{1}\left(\omega, N_{e}\right)}{e\left(\omega, N_{e}\right)}=1
\end{gathered}
$$

Equation (a) fixes the efficiency wage of skilled workers.

The endowment system of the economy is as follows.

$$
\begin{gathered}
a_{\mathrm{K} * 1} \cdot Y_{1}=K^{*}(R, \tau) \\
\text { where } \frac{\delta K^{*}}{\delta R}>0, \frac{\delta K^{*}}{\delta \tau}>0 \\
a_{K 1} \cdot Y_{1}+a_{K 2} \cdot Y_{2}+a_{K 3} \cdot Y_{3}=\bar{K}
\end{gathered}
$$

The rural -urban migration stops when expected urban wage equals the rural wage and thus, equation (7) represents the Harris-Todaro migration equilibrium:

$$
\bar{w} a_{L 2} \cdot Y_{2}+w a_{L 3} \cdot Y_{3}=w \cdot \bar{L}
$$

Total employment of unskilled workers is expressed through the following equation:

$$
a_{L 2} \cdot Y_{2}+a_{L 3} \cdot Y_{3}=L_{e}<\bar{L}
$$

The employment of skilled labour in efficiency unit is expressed as follows:

$$
\frac{a_{N 1}}{e\left(\omega, N_{e}\right)} Y_{1}=N_{e}<\bar{N}
$$

\section{Derivation of Impact of Agricultural Trade Liberalization}

Differentiating equation (3) we have:

We have:

$$
\frac{\hat{a}_{N 1}-\hat{a}_{K 1}}{\hat{\omega}-\hat{r}}=-\sigma^{1}{ }_{N, K}
$$




$$
\begin{aligned}
& \frac{\hat{a}_{L 2}-\hat{a}_{K 2}}{\hat{w}-\hat{\bar{r}}}=-\sigma^{2}{ }_{N, K} \\
& \frac{\hat{a}_{L 3}-\hat{a}_{K 3}}{\hat{w}-\hat{r}}=-\sigma^{3}{ }_{N, K}
\end{aligned}
$$

From equations (5) (6) and (V), (W) (J) we have:

$$
\begin{gathered}
\hat{w}=\frac{1}{\theta_{L 3}} \hat{P}_{3}^{*} \\
\hat{Y}_{2}=-\frac{1}{D} \frac{\hat{P}_{3}^{*}}{\theta_{L 3}}\left[\left(\lambda_{L 2} \theta_{K 2} \frac{\sigma_{L, K}^{2}}{\theta_{K 2}+\theta_{L 2}}+\frac{\lambda_{L 3} \theta_{K 3} \sigma_{L, K}^{3}}{\theta_{L 3}+\theta_{K 3}}\right)+\left(\lambda_{K 2} \theta_{L 2} \frac{\sigma_{L, K}^{2}}{\theta_{K 2}+\theta_{L 2}}+\frac{\lambda_{K 3} \theta_{L 3} \sigma_{L, K}^{3}}{\theta_{L 3}+\theta_{K 3}}\right)\right] \\
\hat{Y}_{3}=\frac{1}{\lambda_{L 3}}\left(\lambda_{L 2} \theta_{K 2} \frac{\sigma_{L, K}^{2}}{\theta_{K 2}+\theta_{L 2}}+\frac{\lambda_{L 3} \theta_{K 3} \sigma_{L, K}^{3}}{\theta_{L 3}+\theta_{K 3}}\right) \frac{1}{\theta_{L 3}} \hat{P}_{3}^{*} \\
-\frac{\lambda_{L 2}}{\lambda_{L 3}} \frac{\bar{w}}{w}\left[-\frac{1}{D} \frac{\hat{P}_{3}^{*}}{\theta_{L 3}}\left\{\left(\lambda_{L 2} \theta_{K 2} \frac{\sigma_{L, K}^{2}}{\theta_{K 2}+\theta_{L 2}}+\frac{\lambda_{L 3} \theta_{K 3} \sigma_{L, K}^{3}}{\theta_{L 3}+\theta_{K 3}}\right)+\left(\lambda_{K 2} \theta_{L 2} \frac{\sigma_{L, K}^{2}}{\theta_{K 2}+\theta_{L 2}}+\frac{\lambda_{K 3} \theta_{L 3} \sigma_{L, K}^{3}}{\theta_{L 3}+\theta_{K 3}}\right)\right\}\right]
\end{gathered}
$$

Where,

$$
D=\eta_{K 2} \eta_{L 3}-\frac{\bar{w}}{w} \eta_{L 2} \eta_{K 3}
$$

Differentiating equation (7) and replacing the values in equation (10) and (11) we have:

$$
\hat{L}_{e}=\lambda_{L 2}\left[1-\frac{\bar{w}}{w}\right]\left[-\frac{1}{D} \frac{\hat{P}_{3}^{*}}{\theta_{L 3}}\left\{\left(\lambda_{L 2} \theta_{K 2} \frac{\sigma_{L, K}^{2}}{\theta_{K 2}+\theta_{L 2}}+\frac{\lambda_{L 3} \theta_{K 3} \sigma_{L, K}^{3}}{\theta_{L 3}+\theta_{K 3}}\right)+\left(\lambda_{K 2} \theta_{L 2} \frac{\sigma_{L, K}^{2}}{\theta_{K 2}+\theta_{L 2}}+\frac{\lambda_{K 3} \theta_{L 3} \sigma_{L, K}^{3}}{\theta_{L 3}+\theta_{K 3}}\right)\right\}\right]
$$

\section{Derivation of Impact of Tariff Restructuring}

Differentiating equation (2) we have,

$$
\hat{r}=\frac{1}{\theta_{K 2}} \hat{t}
$$

Differentiating equation (1), (8) and the standard Solow condition we have:

$$
\hat{\omega}=\frac{1}{e_{K^{*}}^{R} L+\theta_{K_{1}^{*} N e}} \frac{1}{\theta_{K 2}} \hat{t} V
$$




$$
\hat{R}=\left[-\frac{\theta_{K 1}}{\theta_{N 1}+\theta_{K 1}} \frac{1}{\theta_{K 2}} \sigma_{N, K}^{1}+N \frac{1}{e_{K^{*}}^{R} L+\theta_{K_{1}^{*}} N e} \frac{1}{\theta_{K 2}} V\right] \frac{1}{e_{K^{*}}^{R}} \hat{t}
$$

Differentiating equation (3)

$$
\hat{w}=-\frac{\theta_{K 3}}{\theta_{K 2}+\theta_{L 3}} \hat{t}
$$

Differentiating equation (4) we have

$$
\hat{Y}_{1}=e_{K^{*}}^{R} \hat{R}
$$

Replacing equation (22) in (q) we have:

$$
\hat{Y}_{1}=\left[-\frac{\theta_{K 1}}{\theta_{N 1}+\theta_{K 1}} \frac{1}{\theta_{K 2}} \sigma_{N, K}^{1}+N \frac{1}{e_{K^{*}}^{R} L+\theta_{K_{1}^{*}} N e} \frac{1}{\theta_{K 2}} V\right] \hat{t}
$$

From equations (b1), (c1), (V),(W),(J) we have:

$$
\begin{aligned}
& \hat{Y}_{2}=-\frac{1}{D}\left[-\hat{t}\left\{T \lambda_{K 2}+\lambda_{L 3} O\right\}+\lambda_{K 1} \lambda_{L 3}+\left[-\frac{\theta_{K 1}}{\theta_{N 1}+\theta_{K 1}} \frac{1}{\theta_{K 2}} \sigma_{N, K}^{1}+N \frac{1}{e_{K^{*}}^{R} L+\theta_{K_{1}^{*}}^{* N e}} \frac{1}{\theta_{K 2}} V\right]+\hat{t t}\right] \\
& \hat{Y}_{3}=-T \hat{t} \hat{\frac{1}{\lambda}} \frac{1}{\lambda_{L 3}}-\frac{\bar{w}}{w} \frac{\lambda_{L 2}}{\lambda_{L 3}}\left\{-\frac{1}{D}\left[-\hat{t} \hat{t}\left\{T \lambda_{K 2}+\lambda_{L 3} O\right\}+\lambda_{K 1} \lambda_{L 3}+\left[-\frac{\theta_{K 1}}{\theta_{N 1}+\theta_{K 1}} \frac{1}{\theta_{K 2}} \sigma_{N, K}^{1}+N \frac{1}{e_{K}^{R} \cdot L+\theta_{K_{1}^{*}} N e} \frac{1}{\theta_{K 2}} V\right]+\hat{t}\right]\right\}
\end{aligned}
$$

From equation (8), (21) we have:

$$
\hat{N}_{e}=\frac{\omega^{2} e_{11}}{N_{e} e_{2}} \frac{1}{e_{K^{R}}^{R} L+\theta_{K_{1}^{*}} N e} \frac{1}{\theta_{K 2}} \hat{t} \hat{t}
$$

From (d1), (25) and (26) we have:

$$
\begin{aligned}
\hat{L}_{e}= & \frac{1}{\theta_{K 2}} \hat{t} \lambda_{L 2} \theta_{K 2} \frac{1}{\theta_{K 2}+\theta_{L 2}} \sigma_{L, K}^{2}\left(1-\frac{\bar{w}}{w}\right)\left(1+\frac{\theta_{K 3}}{\theta_{L 3}}\right) \\
& +\frac{1}{D}\left[-t \hat{t}\left\{T \lambda_{K 2}+\lambda_{L 3} O\right\}+\lambda_{K 1} \lambda_{L 3}+\left[-\frac{\theta_{K 1}}{\theta_{N 1}+\theta_{K 1}} \frac{1}{\theta_{K 2}} \sigma_{N, K}^{1}+N \frac{1}{e_{K}^{R} L+\theta_{K_{1}} N e} \frac{1}{\theta_{K 2}} V\right]+\hat{t}\right] \lambda_{L 2}\left(1-\frac{\bar{w}}{w}\right)
\end{aligned}
$$


where,

$$
\begin{aligned}
& \mathrm{V}=\frac{\theta_{K 1} \sigma_{N, K}^{1}}{\left(\theta_{N 1}+\theta_{K 1}\right) \theta_{K 2}}\left[e\left(\theta_{K_{1}}{ }^{*}+e_{k^{*}}^{R}\right) \theta_{K 2}-1\right]-e_{K^{*}}^{R} \cdot \theta_{K_{1}}{ }^{*} e \\
& \mathrm{~T}=\frac{1}{\theta_{K 2}}\left\{\frac{\lambda_{L 2} \theta_{K 2}}{\theta_{K 2}+\theta_{L 2}} \sigma_{L, K}^{2}+\frac{\lambda_{L 3} \theta_{K 3} \sigma_{L, K}^{3}}{\theta_{L 3}+\theta_{K 3}}\right\}+\frac{\theta_{K 3}}{\theta_{L 3} \theta_{K 2}}\left\{\frac{\lambda_{L 2} \theta_{K 2} \sigma_{L, K}^{2}}{\theta_{K 2}+\theta_{L 2}}+\frac{\lambda_{L 3} \theta_{K 3} \sigma_{L, K}^{3}}{\theta_{L 3}+\theta_{K 3}}\right\} \\
& \mathrm{O}=\frac{1}{\theta_{K 2}}\left\{\frac{\lambda_{K 2} \theta_{L 2}}{\theta_{K 2}+\theta_{L 2}} \sigma_{L, K}^{2}+\frac{\lambda_{K 3} \theta_{L 3} \sigma_{L, K}^{3}}{\theta_{L 3}+\theta_{K 3}}+\frac{\lambda_{K 1} \theta_{N 1} \sigma_{N, K}^{1}}{\theta_{N 1}+\theta_{K 1}}\right\}+\frac{\theta_{K 3}}{\theta_{L 3} \theta_{K 2}}\left\{\frac{\lambda_{K 2} \theta_{L 2} \sigma_{L, K}^{2}}{\theta_{K 2}+\theta_{L 2}}+\frac{\lambda_{L 3} \lambda_{K 2} \theta_{L 3} \sigma_{L, K}^{3}}{\theta_{L 3}+\theta_{K 3}}\right\} \\
& +\left[-\frac{\lambda_{K 1} \theta_{N 1}}{\theta_{N 1}+\theta_{K 1}} \sigma_{N, K}^{1} \frac{V}{\theta_{K 2}\left\{\theta_{K 1}^{*} e N+L e_{K^{*}}^{R}\right\}}\right] \\
& D=\eta_{K 2} \eta_{L 3}-\frac{\bar{w}}{w} \eta_{L 2} \eta_{K 3} \\
& \mathrm{~L}=\theta_{N 1}+\left(\theta_{K 1}+\theta_{K_{1}^{*}}-1\right)\left(e_{1} \omega+\omega^{2} e_{11}\right)-(1-e) \frac{\theta_{K 1}}{\theta_{N 1}+\theta_{K 1}} \sigma_{N, K}^{1} \\
& \mathrm{~N}=\frac{1}{\lambda_{N 1}}\left[\omega e_{1}+\frac{\omega^{2} e_{11}}{N_{e} e_{2}} e(1-\gamma)+\frac{\lambda_{N 1} Y_{1} \theta_{K 1} \sigma_{N, K}^{1}}{e\left(\theta_{N 1}+\theta_{K 1}\right)}\right]
\end{aligned}
$$

Derivation of Impact of Improvement in General Investment Environment of the Economy

Differentiating equation 4 with respect to $\tau$ we have:

$$
e_{K^{*}}^{R} \hat{R}+e_{K^{*}}^{\tau} \hat{\tau}=\frac{d y_{1}}{y_{1}}
$$

Differentiating equations (5) and (6) we get:

$$
\begin{aligned}
\lambda_{K 1} \hat{y}_{1}+\lambda_{K 2} \hat{y}_{2}+\lambda_{K 3} \hat{y}_{3} & =-\lambda_{K 1} \hat{a}_{K 1} \\
\frac{\bar{w}}{w} \lambda_{l 2} \hat{y}_{2}+\lambda_{l 3} \hat{y}_{3} & =0
\end{aligned}
$$

Differentiating (7) we have

$$
\lambda_{L 2} \hat{y}_{2}+\lambda_{L 3} \hat{y}_{3}=\hat{L}_{e}
$$


From equation (1), (8), (V), (W), (J) and the standard Solow conditions we have:

$$
\begin{gathered}
\hat{\omega}=\frac{1}{e_{K^{\prime}}^{R} L+\theta_{K_{1}^{*}} e N}\left(\theta_{K^{*}}^{1} \cdot e e_{k^{\tau}}^{\tau} \cdot \hat{\tau}\right) \\
\hat{R}=\frac{L}{e_{K^{*}}^{R} L+\theta_{K_{1}} \cdot e N}\left(\theta_{K^{*}}^{1} \cdot e_{k^{\tau}}^{\tau} \cdot \hat{\tau}\right) \frac{1}{\theta_{K_{1}^{*}}}
\end{gathered}
$$

From (14) in al we have

$$
\hat{Y}_{1}=e_{k^{*}}^{\tau} \cdot \hat{\tau}\left[\frac{L}{e_{K^{\prime}}^{R} L+\theta_{K_{1}^{\prime}}^{1} e N}+1\right]
$$

From equations (b1), (c1), (V),(W),(J) we have:

$$
\begin{gathered}
\hat{Y}_{2}=-\frac{1}{D} e_{k^{*}}^{\tau} \hat{\tau}\left[\frac{e_{k^{*}}^{R}}{e_{K^{*}}^{R} L+\theta_{K_{1}^{*}} e N}+1\right] \lambda_{K 1} \lambda_{L 3} \\
\hat{Y}_{3}=\frac{\bar{w}}{w} \frac{\lambda_{L 2}}{\lambda_{L 3}} \frac{1}{D} e_{k^{*}}^{\tau} \hat{\tau}\left[\frac{e_{k^{*}}^{R}}{e_{K^{*}}^{R} L+\hat{\theta}_{K_{1}^{*}} e N}+1\right] \lambda_{K 1} \lambda_{L 3}
\end{gathered}
$$

From equation (8), (13) we have:

$$
\hat{N}_{e}=\frac{\omega^{2} e_{11}}{N_{e} e_{2}} \frac{1}{e_{K^{\prime}}^{R} \cdot L+\theta_{K_{1}^{*}}^{1} e N}\left(\theta_{K^{*}}^{1} \cdot e_{k^{\tau}}^{\tau} \cdot \hat{\tau}\right)
$$

From (d1), (16) and (17) we have:

$$
\begin{gathered}
\hat{L}_{e}=-\lambda_{L 2}\left[1-\frac{1}{\bar{w}} w\right] \frac{1}{D} e_{k^{*}}^{\tau} \hat{\tau}\left[\frac{e_{K^{*}}^{R}}{e_{K^{*}}^{R} L+\theta_{K_{1}^{*}} e N}+1\right] \lambda_{K 1} \lambda_{L 3} \\
D=\eta_{K 2} \eta_{L 3}-\frac{\bar{w}}{w} \eta_{L 2} \eta_{K 3}>0 \\
\mathrm{~L}=\theta_{N 1}+\left(\theta_{K 1}+\theta_{K_{1}^{*}}-1\right)\left(e_{1} \omega+\omega^{2} e_{11}\right)-(1-e) \frac{\theta_{K 1}}{\theta_{N 1}+\theta_{K 1}} \sigma_{N, K}^{1} \\
\mathrm{~N}=\frac{1}{\lambda_{N 1}}\left[\omega e_{1}+\frac{\omega^{2} e_{11}}{N_{e} e_{2}} e(1-\gamma)+\frac{\theta_{K 1} \sigma_{N, K}^{1}}{e\left(\theta_{N 1}+\theta_{K 1}\right)}\right]
\end{gathered}
$$

